\title{
Cinética de degradação ruminal de alimentos proteicos pela técnica in vitro de produção de gases
}

\author{
Ruminal degradation kinetics of protein foods by in vitro gas \\ production technique
}

\author{
Ivone Yurika Mizubuti ${ }^{1,1^{*}}$; Edson Luiz de Azambuja Ribeiro ${ }^{1,1}$; \\ Elzânia Sales Pereira ${ }^{2}$; Eduardo Lucas Terra Peixoto ${ }^{3}$; Elizabeth dos Santos \\ Moura $^{3}$; Odimári Pricila Pires do Prado ${ }^{1}$; Valter Harry Bumbieris Junior ${ }^{1}$; \\ Leandro das Dores Ferreira da Silva ${ }^{1}$; Joyce Maria Cordeiro Cruz ${ }^{3,4}$
}

Resumo

Foram realizadas determinações químico-bromatológicas das frações que constituem os carboidratos e compostos nitrogenados e a determinação das respectivas taxas de digestão do farelo de soja (FS), farelo de crambe (FC), farelo de nabo forrageiro (FNF), resíduo úmido de cervejaria (RUC) e crisálida do bicho da seda desidratada (CBSD). Os parâmetros cinéticos dos carboidratos não fibrosos (CNF) e fração B2 foram estimados a partir da técnica cumulativa de produção de gás. Entre os alimentos estudados houve considerável variação na composição químico-bromatológica. O farelo de crambe foi o único alimento que não apresentou sincronismo entre as frações nitrogenadas e carboidratos. Neste alimento houve predominância das frações $\mathrm{A}+\mathrm{B} 1$ dos carboidratos e $\mathrm{B} 1+\mathrm{B} 2$ dos compostos nitrogenados, sendo que para os demais predominou a fração B2 dos carboidratos e B1+B2 dos compostos nitrogenados. Houve diferença entre os parâmetros de cinética digestiva para todos os alimentos. A maior participação na produção de gases devido aos CNF foi encontrada no farelo de crambe e farelo de nabo forrageiro. A fermentação dos CF proporcionou maior volume de gás no resíduo úmido de cervejaria e no farelo de soja, no entanto, o farelo de soja foi o alimento com maior volume total de gases. A taxa de degradação do CNF do resíduo úmido de cervejaria e crisalida do bicho da seda desidratada estiveram muito abaixo dos limites de degradação dessa fração. Devido aos parâmetros obtidos pela produção cumulativa de gases, o farelo de soja foi o melhor alimento avaliado, no entanto todos os demais apresentam potencial para utilização na nutrição animal. A técnica cumulativa de produção de gases possibilita a estimativa das taxas de degradação e fornece informações adicionais sobre a cinética de fermentação ruminal dos alimentos.

Palavras- chave: Resíduo úmido de cervejaria, crisálida do bicho da seda desidratada, coprodutos

\begin{abstract}
Chemical analysis of carbohydrates and nitrogen fractions, as well as, determination their carbohydrates digestion rates in soyben meal (SM), crambe meal (CM), radish meal (RM), wet brewery residue (WBR) and dehydrated silkworm chrysalis (SCD) were accomplished. The kinetics parameters of
\end{abstract}

\footnotetext{
1 Profs. Drs. do Dept $^{\mathrm{o}}$ de Zootecnia, Centro de Ciências Agrárias, Universidade Estadual de Londrina, UEL, Londrina, PR. 1,1 Bolsistas de Produtividade do CNPq. E-mail: mizubuti@uel.br; elar@uel.br; odimari@uel.br; jrbumbieris@uel.br; leandro@ uel.br

2 Prof $^{a}$ Dr $^{\mathrm{a}}$ do Dept ${ }^{\mathrm{o}}$ de Zootecnia, Centro de Ciências Agrárias, Universidade Federal de Fortaleza, CCA/UFC, Fortaleza, CE. Bolsista de Produtividade do CNPq. E-mail: elzania@hotmail.com

3 Discentes de Doutorado do Programa de Pós-graduação em Ciência Animal, UEL, Londrina, PR. E-mail: eduzootec@hotmail. com; esmoura@zootecnista.com.br

4 Prof ${ }^{a}$ M.e da Universidade Tecnológica Federal do Paraná, UTFPR, Campus Cornélio Procópio, Cornélio Procópio, PR. E-mail: joyce@utfpr.edu.br

* Autor para correspondência
} 
non-fibrous carbohydrates (NFC) and B2 fraction were estimated using cumulative gas production technique. Among the foods studied there was considerable variation in chemical composition. The crambe meal was the only food that did not present synchronism between carbohydrate and nitrogen fractions. In this food there was predominance of $\mathrm{A}+\mathrm{B} 1$ carbohydrates fractions and $\mathrm{B} 1+\mathrm{B} 2$ nitrogen compounds fraction, and for the other predominated $\mathrm{B} 2$ carbohydrate fraction and $\mathrm{B} 1+\mathrm{B} 2$ nitrogen compounds fraction. There were differences among the digestive kinetic parameters for all foods. The greater participation in gas production due to non-fibrous carbohydrates was found in the crambe meal and oilseed radish meal. The fermentation of fibrous carbohydrates provided higher gas volume in the wet brewery residue and in the soybean meal, however, the soybean meal was food with higher total gas volume. Non fibrous carbohydrates degradation rates of wet brewery residue and dehydrated silkworm chrysalis were far below the limits of degradation of this fraction. Due to the parameters obtained by the cumulative gas production, the soybean meal was the best food, however, all others have potential for use in animal nutrition. The cumulative gas production technique allows the estimative of degradation rates and provides further information about the ruminal fermentation kinetics of foods.

Key words: Wet brewery residue, dehydrated silkworm chrysalis, coproducts

\section{Introdução}

O valor nutritivo de um alimento depende de sua composição química e do nível de aproveitamento dos nutrientes pelos animais, sendo que nos animais ruminantes este aproveitamento é decorrente da simbiose entre o animal e a microbiota ruminal. Tal simbiose permite a utilização indireta de carboidratos estruturais inaccessíveis à ação enzimática dos mamíferos. Todavia, a quantidade de nutrientes ingeridos que realmente é absorvida depende da taxa de fermentação ruminal e do tempo de permanência e exposição ao ataque microbiano, pois a fração efetivamente degradada é função das taxas de degradação e de passagem. Além disso, a taxa e a extensão de degradação ruminal dependem, principalmente, da natureza e do teor dos componentes da parede celular e da disponibilidade ruminal de nitrogênio. Assim, os sistemas químicos de análise, juntamente com a cinética de degradação ruminal, possibilitam a estimativa mais precisa do valor nutritivo das forragens (MELLO et al., 2006).

Atualmente, metodologias de avaliação de alimentos para ruminantes objetivam rapidez, baixo custo e confiabilidade. Aliado a este fato, os sistemas atuais de adequação de dietas para ruminantes necessitam da composição e características dos alimentos, dentre as quais, informações no que diz respeito às suas frações de carboidratos e proteínas, bem como de suas taxas de digestão, para que se possa estimar com maior exatidão o desempenho dos animais e maximizar a eficiência de utilização dos nutrientes (MOREIRA, et al. 2010). A técnica de produção cumulativa de gases tem sido amplamente utilizada nos laboratórios de nutrição de ruminantes, por ser simples e de baixo custo. São vantagens da técnica sua simplicidade de uso e a possibilidade de processar grande número de amostras em curto espaço de tempo e uniformidade físico-química do meio (MALAFAIA et al., 1998; BARCELOS et al., 2001).

Atécnicadeprodução degás considera a conversão de todas as principais fontes de carboidratos como monossacarídeos, polissacarídeos, pectinas, amido, celulose e hemicelulose, em $\mathrm{CO}_{2}$ e $\mathrm{CH}_{4}$ e, também, a reação dos AGV com o tampão bicarbonato. Assim, esse método pode ser utilizado para determinar a importância de algumas dessas diferentes frações do alimento, em fornecer energia aos microorganismos (PELL; SCHOFIELD, 1993). A técnica ainda assume que a produção de massa celular bacteriana e de gás é proporcional à quantidade de substrato digerido.

Os pontos críticos do método de produção de gás são: 1) pequena quantidade de amostra, tornando maiores os erros experimentais, 2) dificuldades na conservação e padronização de alimentos, para correção dos desvios causados pela mudança na atividade microbiana do líquido ruminal, 3) o 
alimento pode ter baixa produção de gás, mas na digestão in vivo pode ter alta digestibilidade e 4) o $\mathrm{pH}$ dos alimentos e do líquido ruminal, no processo de digestão, pode influenciar negativamente o crescimento microbiano, acarretando em menor taxa de degradação do alimento ao final da incubação (CAMPOS et al., 2000).

Diante do exposto, objetivou-se com este trabalho determinar a composição bromatológica, as frações de carboidratos e dos compostos nitrogenados e a cinética e taxas de degradação in vitro de alguns alimentos proteicos (farelos de soja, crambe e nabo forrageiro, resíduo úmido de cervejaria e crisálida do bicho da seda desidratada) por meio da técnica de produção de gases e estimar o valor energético dos alimentos por meio das equações preditas pelo National Research Council (2001).

\section{Material e Métodos}

Foram avaliadas amostras dos farelos de soja (Glycine max (L.)), crambe (Crambe abyssinica), nabo forrageiro (Raphanus sativus (L.)), resíduo úmido de cervejaria e crisálida do bicho da seda (Bombix mori) desidratada.

O fracionamento dos carboidratos foi realizado no Laboratório de Nutrição Animal do Departamento de Zootecnia da Universidade Estadual de Londrina. Inicialmente os alimentos foram analisados para determinação da matéria seca (MS), matéria orgânica (MO), matéria mineral $(\mathrm{MM})$, proteína bruta $(\mathrm{PB})$, extrato etéreo $(\mathrm{EE})$, lignina (LIG), fibra em detergente neutro (FDN) e fibra em detergente ácido (FDA), conforme técnicas descritas por Mizubuti et al. (2009).

As frações dos carboidratos foram obtidas, utilizando-se a metodologia descrita por Sniffen et al. (1992), onde:

Carboidratos totais: CHT $(\% \mathrm{MS})=100-\mathrm{PB}$ (\%MS) - EE (\%MS) - MM (\%MS);

Fracão "C" (\%MS) = FDN (\%MS) x 0,01 x LIG $(\% \mathrm{FDN}) \times 2,4$;
Fração "B2" (\%MS) = FDNcp - Fração "C";

Fração "A + B1" = CHT (\%MS) - (Fração "B2" Fração "C");

sendo, $\mathrm{PB}=$ Proteína bruta $(\mathrm{N} x$ 6,25) $; \mathrm{FDN}=$ Fibra em detergente neutro; FDNcp = Fibra em detergente neutro corrigida para os teores de cinza e proteína; $\mathrm{EE}=$ Extrato etéreo; $\mathrm{MM}=$ Matéria mineral.

O fracionamento dos compostos nitrogenados foi realizado de acordo com o protocolo descrito por Malafaia e Vieira (1997), adaptado por Morenz (2004).

A Fração "A" ou compostos nitrogenados não proteicos (NNP) foi obtida após o tratamento de $0,5 \mathrm{~g}$ de amostra com $50 \mathrm{~mL}$ de água por 30 minutos, e depois, adição de $10 \mathrm{~mL}$ da solução de ácido tricloroacético (TCA) a 10\%, deixando-se em repouso por mais 30 minutos. Em seguida, filtrou-se em papel de filtro de filtragem rápida, e determinouse o teor de nitrogênio do resíduo mais o papel. A fração A ou NNP foi calculada pela diferença entre o teor de $\mathrm{N}$-total e o de $\mathrm{N}$-insolúvel no TCA.

A Fração "B3" foi determinada pela diferença entre o $\mathrm{N}$ insolúvel em detergente neutro (NIDN) e o $\mathrm{N}$ insolúvel em detergente ácido (NIDA).

A Fração "C" foi obtida pela determinação de NIDA. Obteve-se a fração "B1 + B2", pela diferença entre o N insolúvel em TCA e o NIDN, ou subtraindo-se de 100 a soma das frações A, B3 e C.

Para a estimativa dos valores de nutrientes digestíveis totais (NDT), os cálculos foram realizados de acordo com a seguinte fórmula (NRC, 2001): \%NDT $=\%$ CNF-d $+\%$ PB-d $+(\%$ AG-d $x$ $2,25)+\%$ FDNn-d -7 , em que: CNF-d corresponde aos carboidratos não fibrosos digestíveis, PB-d à proteína bruta digestível, AG-d aos ácidos graxos digestíveis, FDNn-d à fibra em detergente neutro corrigida para nitrogênio digestível e o valor 7 referese ao NDT fecal metabólico, ou seja, à correção utilizada, uma vez que as frações digestíveis dos alimentos consideradas para o cálculo do NDT referem-se à digestibilidade verdadeira e não à 
aparente. Para o cálculo do \%CNF-d, utilizou-se a seguinte equação: \%CNF-d $=0,98$ x $[100-(\% \mathrm{~PB}$ $+\% \mathrm{EE}+\% \mathrm{FDNn}+\% \mathrm{MM})] \mathrm{x}$ PAF, onde: PAF é um fator de ajuste igual a 1 para todos os outros alimentos, conforme NRC (2001).

Para o cálculo da \%PB-d, foram utilizadas as equações para alimentos concentrados: \%PB-d = [1-(0,4 x $(\% \mathrm{PIDA} / \% \mathrm{~PB}))]$ x \%PB. Para o cálculo de \%AG-d foram utilizadas as seguintes equações: $\%$ AG-d $=\% \mathrm{EE}-1$, para $\% \mathrm{EE}>1$, sendo que, para alimentos com teores de $\mathrm{EE}<1, \mathrm{AG}-\mathrm{d}=0$. Para o cálculo de \%FDN-d, utilizou-se a expressão: $\%$ FDNn-d $=0,75 \times(\%$ FDNn $-\%$ LIG $) \times[1-$ $\left.(\% \mathrm{LIG} / \% \mathrm{FDNn})^{0,667}\right]$, onde: $\% \mathrm{FDNn}=\% \mathrm{FDN}-$ $\%$ PIDN.

Foram calculados os valores de energia digestível (ED, Mcal $/ \mathrm{kg}$ ), energia metabolizável produtiva (EMp, Mcal $/ \mathrm{kg}$ ) e energia líquida de lactação (ELL, Mcal $/ \mathrm{kg}$ ), conforme as seguintes equações propostas pelo NRC (2001):

$\mathrm{ED}(\mathrm{Mcal} / \mathrm{kg})=(\mathrm{CNF}-\mathrm{d} / 100) \times 4,2+(\mathrm{FDN}-\mathrm{d} / 100)$ x 4,2+(PB-d/100) x 5,6+(AG-d/100) x 9,4-0,3;

$\operatorname{EMp}(\mathrm{Mcal} / \mathrm{kg})=(1,01 \times \mathrm{ED}-0,45)+0,0046 \times$ $(\mathrm{EE}-3)$;

\section{$\operatorname{ELL}(\mathrm{Mcal} / \mathrm{kg})=[0,703 \times \mathrm{EMp}]-0,19$}

As taxas de digestão das frações de carboidratos (CNF e B2) foram estimadas, utilizando-se a técnica de produção de gases, seguindo protocolo descrito por Pell e Schofield (1993), com modificações.

Foram incubadas, aproximadamente, $50 \mathrm{mg}$ de cada amostra, em frascos de vidro $(50 \mathrm{~mL})$. Adicionou-se, a cada frasco, $8 \mathrm{~mL}$ de solução tampão de McDougal (McDOUGAL, 1949), reduzido previamente, a partir de aspersão com $\mathrm{CO}_{2}$, para ajuste do $\mathrm{pH}(8,6)$ à faixa de $6,8-7,0$, e $2 \mathrm{~mL}$ de líquido ruminal, coletados diretamente do rúmen de dois bovinos recém abatidos em frigorífico, sendo que os conteúdos ruminais foram homogeneizados e acondicionados em garrafas térmicas previamente aquecidas com água a $39^{\circ} \mathrm{C}$, e posteriormente filtrados em camada dupla de gaze. A adição da solução tampão e do inóculo foi realizada sob aspersão de $\mathrm{CO} 2$, para garantir as condições anaeróbicas. Os frascos foram imediatamente vedados com tampa de borracha e lacrados e, então, mantidos em estufa incubadora BOD a $39^{\circ} \mathrm{C}$. As leituras de pressão foram realizadas nos tempos: 0 , $1,2,3,4,5,6,9,12,18,24,30,36,48,60,72,84,96$ e 144 horas, utilizando-se um "sensor de pressão", conectado a um manômetro (PELL; SCHOFIELD, 1993). Para converter os valores de pressão para volumes utilizou-se a equação para altitude local obtida após 2330 leituras de volume e pressão em diferentes tipos de alimentos, $\mathrm{V}=0,5702+3,2399 \mathrm{p}$ $+0,1074 \mathrm{p}^{2}, \mathrm{R}^{2} 0,9872$, onde $\mathrm{V}=$ volume total de gases e "p" é a pressão dos gases dentro dos frascos de fermentação (psi = pressão por polegada quadrada).

A cinética da produção cumulativa dos gases foi analisada empregando-se o modelo logístico bicompartimental (SCHOFIELD; PITT; PELL, 1994):

\section{$\mathrm{V}(\mathrm{t})=\mathrm{Vcnf} /(1+\exp (2-4 * \mathrm{kcnf} *(\mathrm{~T}-\mathrm{L})))+$ \\ $\mathrm{Vcf} /\left(1+\exp \left(2-4 * \mathrm{kcf}^{*}(\mathrm{~T}-\mathrm{L})\right)\right)$}

onde: $\mathrm{V}(\mathrm{t})$ é o volume acumulado no tempo t; Vcnf é o volume de gás produzido a partir da fração de rápida digestão $(\mathrm{CNF}) ; \mathrm{kcnf}(\% / \mathrm{h})$ é a taxa de degradação da fração de rápida digestão (CNF); L, a latência; e T, o tempo (h); Vcf é o volume de gás produzido a partir da fração de lenta degradação (B2); kcf (\%/h) é a taxa de degradação da fração B2.

$\mathrm{O}$ delineamento experimental dos ensaios de fermentação in vitro foi inteiramente casualizado, em que os tratamentos consistiram nos cinco alimentos e quatro repetições. As médias foram comparadas pelo teste SNK a 5\% de probabilidade com o auxílio do programa SAS (2009).

As estimativas dos parâmetros descritos no modelo matemático foram desenvolvidas utilizandose métodos interativos não lineares. Estes resultados ajustados, por estimativas de quadrados mínimos, foram obtidos a partir do método Gauss - Newton, dentro do procedimento NLIN, com o auxílio do programa SAS (2009). 


\section{Resultados e Discussão}

Os teores dos nutrientes obtidos para o resíduo úmido de cervejaria (RCU) (Tabela 1) apresentaramse próximos à variação observada na literatura (CABRAL FILHO; BUENO; ABDALLA, 2007; GERON et al., 2007; SILVA et al., 2010). A elevada quantidade de umidade do RUC pode resultar em fatores limitantes, tais como: dificuldade de transporte por longas distâncias, dificuldades no armazenamento e redução no consumo de nutrientes (EASTRINDGE, 1991; SILVA et al., 2010).

A crisálida do bicho da seda desidratada (CBSD) apresentou teores de proteína bruta próximo aos valores encontrados na literatura (LIMA et al., 1990; COLL et al., 1992), sendo este valor 13\% superior ao teor de PB do farelo de soja (FS). Outro aspecto que se verificou na CBSD foi o elevado teor de extrato etéreo $(30,7 \%$ na MS $)$, cujo teor faz com que este alimento apresente em sua composição energética (Tabela 2) maiores conteúdos de nutrientes digestíveis totais (NDT), energia digestível (ED), energia metabolizável de produção (EMp) e energia líquida de lactação (ELL) do que os demais alimentos, sendo superior ao farelo de soja em 39,0; 35,$5 ; 39,8$ e 42,0\%, respectivamente, para cada uma das unidades energética. Por outro lado, esse elevado teor de EE dificulta o armazenamento do produto, tornando-o mais susceptível a processos de oxidação e rancificação. Outra característica desse alimento é o baixo teor de fibra, decorrente do fato da CBSD ser um inseto e não conter em sua composição fibra de parede celular vegetal. A pequena quantidade de fibra encontrada pode ser resultado de resquícios de fragmentos do casulo de seda.

Tabela 1. Composição bromatológica dos alimentos proteicos (g/kgMS).

\begin{tabular}{lccccc}
\hline Farelo de soja & $\begin{array}{c}\text { Resíduo úmido } \\
\text { de cervejaria }\end{array}$ & $\begin{array}{c}\text { Farelo de } \\
\text { crambe }\end{array}$ & $\begin{array}{c}\text { Farelo de } \\
\text { nabo forrageiro }\end{array}$ & $\begin{array}{c}\text { Crisálida do bicho da seda } \\
\text { desidratada }\end{array}$ \\
\hline MS $^{1}$ & 955,9 & 155,3 & 885,9 & 886,0 & 984,9 \\
$\mathrm{MO}^{2}$ & 936,2 & 994,5 & 917,5 & 893,7 & 966,5 \\
$\mathrm{~PB}^{3}$ & 467,3 & 246,5 & 321,3 & 444,4 & 538,2 \\
$\mathrm{EE}^{4}$ & 20,3 & 62,9 & 1,9 & 3,6 & 307,3 \\
$\mathrm{FDN}^{5}$ & 249,2 & 579,4 & 290,8 & 212,9 & 32,6 \\
$\mathrm{FDA}^{6}$ & 167,6 & 224,9 & 258,9 & 168,7 & 16,4 \\
$\mathrm{LIG}^{7}$ & 1,99 & 64,7 & 7,27 & 2,46 & 0,25 \\
\hline
\end{tabular}

${ }^{1} \mathrm{MS}$ - matéria seca, ${ }^{2} \mathrm{MO}$ - matéria orgânica, ${ }^{3} \mathrm{~PB}$ - proteína bruta, ${ }^{4} \mathrm{EE}$ - extrato etéreo, ${ }^{5} \mathrm{FDN}$ - fibra em detergente neutro, ${ }^{6} \mathrm{FDA}$ - fibra em detergente ácido, ${ }^{7} \mathrm{LIG}$ - lignina.

Fonte: Elaboração dos autores.

Tabela 2. Nutrientes digestíveis totais (NDT, g/kg de MS), energia digestível (ED, Mcal/kg), energia metabolizável de produção (EMp, Mcal/kg) e energia líquida de lactação (ELL, Mcal $/ \mathrm{kg}$ ) nos alimentos experimentais.

\begin{tabular}{lccccc}
\hline Farelo de soja & $\begin{array}{c}\text { Resíduo úmido de } \\
\text { cervejaria }\end{array}$ & $\begin{array}{c}\text { Farelo de } \\
\text { crambe }\end{array}$ & $\begin{array}{c}\text { Farelo de } \\
\text { nabo forrageiro }\end{array}$ & $\begin{array}{c}\text { Crisálida do bicho da } \\
\text { seda desidratada }\end{array}$ \\
\hline NDT & 760,3 & 698,8 & 652,4 & 715,1 & 1245,0 \\
ED & 3,9 & 3,3 & 3,3 & 3,8 & 6,0 \\
EMp & 3,5 & 2,9 & 2,9 & 3,4 & 5,7 \\
ELL & 2,3 & 1,8 & 1,8 & 2,2 & 3,8 \\
\hline
\end{tabular}

Fonte: Elaboração dos autores. 
A composição dos farelos de soja (FS), de crambe (FC) e de nabo forrageiro (FNF) foi compatível com os resultados encontrados na literatura (PERRY et al., 1979; ANDERSON et al., 1993; FERNANDES et al. 2009; SANTOS et al., 2010).

No entanto, observou-se que os alimentos avaliados por se tratarem de coprodutos industriais apresentaram algumas variações em sua composição química decorrentes do processo produtivo, seja por mudanças no cultivar, tipo de solo, época do ano, forma de processamento, tempo de armazenamento e temperatura ambiente. Sendo assim, as composições químicas encontradas representam um indicativo da qualidade nutricional do alimento.

Com relação aos valores energéticos, em nutrientes digestíveis totais (NDT), energia digestível (ED), energia metabolizável de produção (EMp) e energia líquida de lactação (ELL) nos alimentos experimentais, observou-se que a crisalida do bicho da seda desidratada, farelo de soja e farelo de nabo forrageiro apresentaram valores superiores em relação aos demais coprodutos (Tabela 2). O resíduo úmido de cervejaria apresentou maior teor de EE quando comparado ao farelo de soja, mas isto não foi suficiente para elevar o seu conteúdo energético, pois para o cálculo do NDT levam-se em consideração outros nutrientes capazes de gerar energia como carboidratos e proteínas digeríveis. Neste caso, o resíduo úmido de cervejaria apresentou em sua composição elevado teor de FDN e uma fração lignificada seis vezes superior ao farelo de soja.

Nas frações de carboidratos (Tabela 3) observouse que RUC apresentou maior teor de carboidratos totais, sendo que desse componente, $75,4 \%$ foi representado pela fração B2 dos carboidratos. Outro alimento que apresentou elevados teores da fração B2 foi o farelo de soja (FS) que correspondeu a $52 \%$ dos carboidratos totais. Segundo Sniffen et al. (1992), a fração B2 é de degradação lenta e corresponde à parede celular disponível. De acordo com Russell et al. (1992) alimentos com elevado teor de fração B2 demandam fontes de nitrogênio não proteico para atender a demanda de $\mathrm{N}$ dos microrganismos fermentadores de carboidratos estruturais. Embora essa população microbiana não utilize a proteína verdadeira diretamente, a fermentação de aminoácidos de cadeia ramificada gera os ácidos graxos de cadeia ramificada, necessários para o crescimento dos microrganismos fibrolíticos.

Tabela 3. Frações dos carboidratos dos alimentos com base nos teores de matéria seca ( $\mathrm{g} / \mathrm{Kg}$ de $\mathrm{MS}$ ) e carboidratos totais $(\mathrm{g} / \mathrm{kg}$ de $\mathrm{CT})$.

\begin{tabular}{lccccc}
\hline & $\begin{array}{c}\text { Farelo de } \\
\text { soja }\end{array}$ & $\begin{array}{c}\text { Resíduo } \\
\text { úmido de } \\
\text { cervejaria }\end{array}$ & $\begin{array}{c}\text { Farelo de } \\
\text { crambe }\end{array}$ & $\begin{array}{c}\text { Farelo de } \\
\text { nabo } \\
\text { forrageiro }\end{array}$ & $\begin{array}{c}\text { Crisálida do bicho da } \\
\text { seda desidratada }\end{array}$ \\
\hline $\mathrm{CT}(\mathrm{g} / \mathrm{kg}$ de MS) & 448,7 & 685,2 & 594,3 & 445,7 & 120,9 \\
$\mathrm{~A}+\mathrm{B} 1(\mathrm{~g} / \mathrm{kg}$ de $\mathrm{MS})$ & 209,7 & 116,0 & 313,7 & 243,0 & 98,6 \\
$\mathrm{~B} 2(\mathrm{~g} / \mathrm{kg}$ de MS) & 236,0 & 517,0 & 265,9 & 200,0 & 22,3 \\
$\mathrm{C}(\mathrm{g} / \mathrm{Kg}$ de $\mathrm{MS})$ & 3,0 & 52,2 & 14,8 & 2,7 & 0,0 \\
\hline $\mathrm{A}+\mathrm{B} 1(\mathrm{~g} / \mathrm{kg}$ de $\mathrm{CT})$ & 467,4 & 169,3 & 527,8 & 545,2 & 815,4 \\
$\mathrm{~B} 2(\mathrm{~g} / \mathrm{kg}$ de $\mathrm{CT})$ & 526,0 & 754,5 & 447,4 & 448,8 & 184,5 \\
$\mathrm{C}(\mathrm{g} / \mathrm{kg}$ de $\mathrm{CT})$ & 6,6 & 76,1 & 24,8 & 6,0 & 0,1 \\
\hline
\end{tabular}

Fonte: Elaboração dos autores. 
Para os demais alimentos houve a predominância da fração $\mathrm{A}+\mathrm{B} 1$, que corresponde aos açucares solúveis, amido e pectina, com alta taxa de degradação (SNIFFEN et al., 1992). Alimentos com elevada proporção da fração A+B1 são considerados boas fontes de energia para o crescimento de microrganismos que utilizam CNF. Contudo, é necessária a inclusão de fontes proteicas de rápida e média degradação no rúmen quando a fração $\mathrm{A}+\mathrm{B} 1$ compõe a principal fração dos carboidratos da dieta objetivando a sincronização entre a liberação de energia e nitrogênio (VALADARES FILHO, 2000). A fração $\mathrm{C}$ foi relativamente baixa para todos os alimentos avaliados, devido ao baixo teor de lignina nos alimentos estudados.

$\mathrm{Na}$ avaliação das frações nitrogenada (Tabela 4) verificou-se que houve maior predominância da fração nitrogenada $\mathrm{B} 1+\mathrm{B} 2$ na maioria dos alimentos estudados (FS, RUC, farelo de crambe (FC) e
CBSD), entretanto, no farelo de nabo forrageiro (FNF), predominou a fração $\mathrm{A}$ dos compostos nitrogenados. Observou-se que, com exceção do farelo de crambe, houve um sincronismo entre as frações de carboidratos e compostos nitrogenados para os demais alimentos (FS, RUC, FNF e CBSD), favorecendo assim eficiência de utilização de energia, reduzindo a excreção de compostos nitrogenados no solo e potencializando o crescimento de bactérias utilizadoras de carboidratos estruturais (NOCEK; RUSSELL, 1988). Segundo Russell et al. (1992), fontes de nitrogênio não proteico (NNP) são fundamentais para o bom funcionamento ruminal, pois os microrganismos ruminais fermentadores de carboidratos estruturais, utilizam amônia como fonte de nitrogênio. Todavia, altas proporções de NNP podem resultar em perdas nitrogenadas, se houver deficiência de esqueleto de carbono prontamente disponível para a síntese de proteína microbiana.

Tabela 4. Frações nitrogenadas dos alimentos com base nos teores de matéria seca (g/kg de MS) e proteína bruta (g/ $\mathrm{kg}$ de PB).

\begin{tabular}{lccccc}
\hline & $\begin{array}{c}\text { Farelo de } \\
\text { soja }\end{array}$ & $\begin{array}{c}\text { Resíduo } \\
\text { úmido de } \\
\text { cervejaria }\end{array}$ & $\begin{array}{c}\text { Farelo de } \\
\text { crambe }\end{array}$ & $\begin{array}{c}\text { Farelo de } \\
\text { nabo } \\
\text { forrageiro }\end{array}$ & $\begin{array}{c}\text { Crisálida do } \\
\text { bicho da seda } \\
\text { desidratada }\end{array}$ \\
\hline $\mathrm{A}(\mathrm{g} / \mathrm{kg}$ de MS) & 144,5 & 4,6 & 51,0 & 382,0 & 101,1 \\
$\mathrm{~B} 1+\mathrm{B} 2$ (g/kg de MS) & 312,6 & 179,8 & 249,7 & 42,1 & 428,0 \\
$\mathrm{~B} 3(\mathrm{~g} / \mathrm{kg}$ de $\mathrm{MS})$ & 9,9 & 7,1 & 17,1 & 16,6 & 8,5 \\
$\mathrm{C}(\mathrm{g} / \mathrm{kg}$ de $\mathrm{MS})$ & 0,3 & 0,7 & 3,5 & 3,7 & 0,6 \\
\hline $\mathrm{A}(\mathrm{g} / \mathrm{kg}$ de $\mathrm{PB})$ & 309,2 & 196,6 & 158,7 & 859,7 & 187,9 \\
$\mathrm{~B} 1+\mathrm{B} 2(\mathrm{~g} / \mathrm{kg}$ de $\mathrm{PB})$ & 668,9 & 770,3 & 777,1 & 94,7 & 795,3 \\
$\mathrm{~B} 3(\mathrm{~g} / \mathrm{kg}$ de $\mathrm{PB})$ & 21,3 & 30,3 & 53,2 & 37,3 & 15,8 \\
$\mathrm{C}(\mathrm{g} / \mathrm{kg}$ de $\mathrm{PB})$ & 0,6 & 2,8 & 11,0 & 8,3 & 1,0 \\
\hline
\end{tabular}

Fonte: Elaboração dos autores.

Houve diferença $(\mathrm{P}<0,05)$ para volume e taxa de degradação dos carboidratos não fibrosos e fibrosos, tempo de latência e volume total de gás, obtidos pela produção cumulativa de gases (Tabela 5 e Figura 1).

A fermentação dos carboidratos totais gerou um maior volume final de gás para o farelo de soja
(78,16 mL), seguido de resíduo úmido de cervejaria $(52,2 \mathrm{~mL})$ e farelo de crambe $(51,4 \mathrm{~mL}$ de gás). $\mathrm{O}$ farelo de nabo forrageiro produziu $38,6 \mathrm{~mL}$ de gás, ao passo que a crisalida do bicho da seda foi a que gerou menor volume de gás (18,9 mL) (Figura 1), que pode ter sido ocasionada pela fermentação da 
proteína solúvel que gera amônia como principal metabolito. Segundo Cabral et al. (2000) a concentração de amônia oriunda da fermentação de proteína, também influencia no equilíbrio do tampão bicarbonato, por capturar íons $\mathrm{H}^{+}$e prevenir a liberação de $\mathrm{CO}_{2}$, sendo que, cada mmol de amônia produzida impede a liberação de $0,87 \mathrm{mmol}$ de gás.

Nas primeiras horas de incubação, quase 100\% dos gases produzidos no sistema corresponderam aos carboidratos não fibrosos, sendo a principal fonte de energia para o crescimento microbiano (Figura 1). Os gases gerados pelos carboidratos não fibrosos representaram do volume total de gases produzido, em média, 55,7 (FS); 50,3 (RUC); 78,0 (FC); 85,1 (FNF) e 59,4\% (CBSD), respectivamente. Este comportamento na produção de gases foi semelhante aos resultados obtidos por Mizubuti et al. (2011) ao trabalharem com alguns co-produtos gerados na cadeia produtiva do biodiesel.
A superioridade do farelo de crambe (FC) e de nabo forrageiro (FNF) em relação ao farelo de soja (FS) no volume de gás dos carboidratos não fibrosos deve-se ao maior teor da fração $\mathrm{A}+\mathrm{B} 1$ dos carboidratos e maior taxa de degradação de carboidratos não fibrosos desses alimentos (Tabela 5). Segundo Stefanon, Pell e Schofield (1996) e Cone, Van Gelder e Driehuis (1997), alterações no volume de gás da fração de carboidratos não fibrosos após 24 horas, estão relacionadas ao turnover microbiano e às mudanças na taxa de digestão de FDN. Ainda, segundo Stefanon, Pell e Schofield (1996), a fração dos carboidratos solúveis em água, não é bem definida quimicamente, devido às diferentes proporções de pectina, frutosanas e amido contidas nos alimentos. Entretanto, esta fração tem alto valor nutricional para os microrganismos do rúmen. Consequentemente, essas frações solúveis dos alimentos contribuem muito para produção de ácidos graxos voláteis, fonte de energia para os ruminantes.

Figura 1. Volume final de gás produzido durante a incubação in vitro dos farelos de soja, crambe e nabo forrageiro, resíduo úmido de cervejaria (RUC) e crisálida do bicho da seda desidratada.

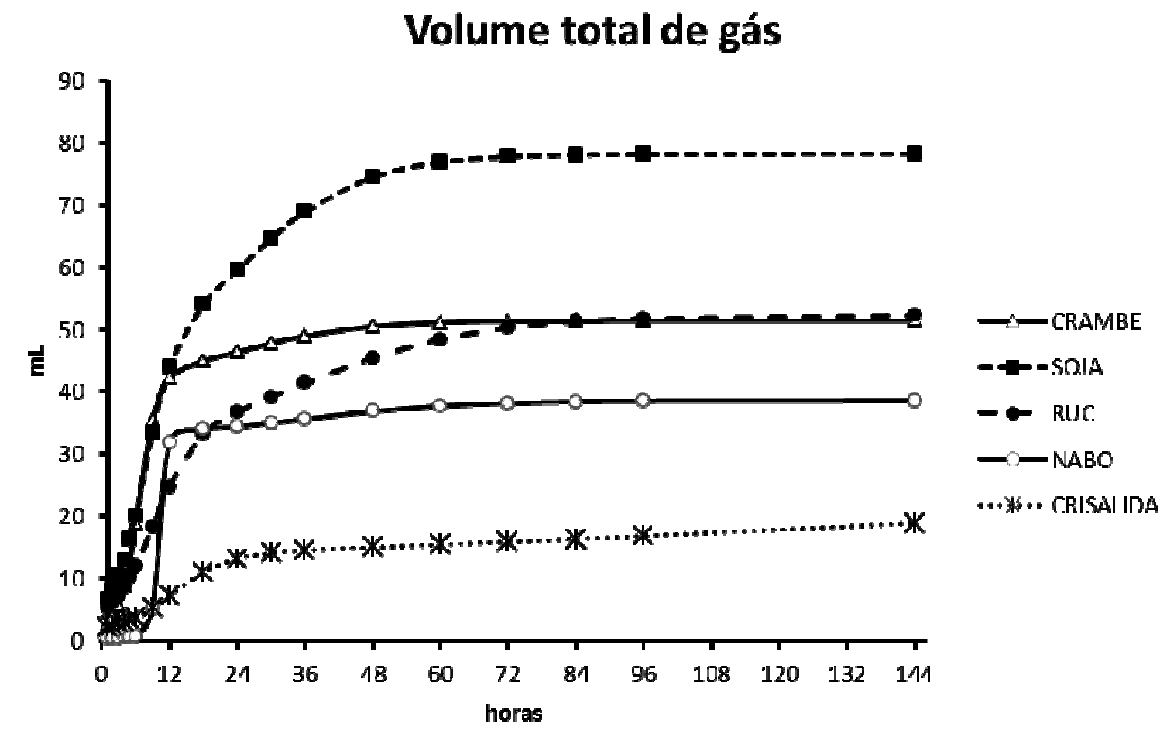

Fonte: Elaboração dos autores.

A taxa de degradação dos carboidratos não fibrosos (CNF) do RUC e CBSD (Tabela 3) apresentaram-se abaixo dos limites preconizados por Sniffen et al. (1992), que é de 10 a $40 \% / \mathrm{h}$. A reduzida taxa de digestão estimada para os CNF destes alimentos pode ser atribuída à natureza 
desta fração, que neste caso, é representada principalmente por ácidos orgânicos, uma vez que os grãos de amido do RUC sofreram fermentação durante o processamento da cerveja e a CBSD por ser um produto de origem animal não é capaz de sintetizar amido. Segundo Cabral et al. (2002) o acúmulo de metabólitos (ácidos orgânicos) em taxas elevadas ao ambiente de incubação, ou até mesmo a exaustão de outros nutrientes $(\mathrm{N})$, pode inibir a ação fermentativa, embora ainda existam nutrientes potencialmente digestíveis.

A contribuição dos carboidratos fibrosos na produção de gás foi de 49,7\% (RUC); 44,3\% (FS); $40,6 \%$ (CBSD); 22,0\% (FC) e 14,9\% (FNF). O maior volume de gás produzido pela degradação dos carboidratos fibrosos do RUC e do FS em relação aos demais alimentos foi devido ao maior teor da fração B2 dos carboidratos desses alimentos. Ainda que as frações dos alimentos possam ser caracterizadas como de rápida ou de lenta digestão, diferenças de natureza química e estruturais dos alimentos poderiam ser responsabilizadas por diferentes graus de utilização dessas frações pelos microrganismos (BEZERRA et al., 2005).

Dentre os alimentos nota-se que o RUC foi o segundo alimento com a menor taxa de degradação dos carboidratos fibrosos, quando comparado com os demais (Tabela 3). Essa menor taxa de degradação é devido ao elevado teor de lignina encontrado no RUC, que acarreta em maior fração $\mathrm{C}$ dos carboidratos, fração esta indigerível. Para a crisalida do bicho da seda desidratada, a baixíssima taxa de degradação é resultante da quase inexistência de componentes fibrosos em sua constituição, aliado ao fato das fontes proteicas de origem animal apresentarem menor degradação ruminal do que fontes de origem vegetal (PEREIRA et al., 2008).

Tabela 5. Volumes e taxas de degradação dos carboidratos não fibrosos e fibrosos obtidos pela técnica de produção cumulativa de gases dos alimentos.

\begin{tabular}{lccccccc}
\hline & $\begin{array}{c}\text { Farelo de } \\
\text { soja }\end{array}$ & $\begin{array}{c}\text { Resíduo } \\
\text { úmido de } \\
\text { cervejaria }\end{array}$ & $\begin{array}{c}\text { Farelo de } \\
\text { crambe }\end{array}$ & $\begin{array}{c}\text { Farelo de } \\
\text { nabo } \\
\text { forrageiro }\end{array}$ & $\begin{array}{c}\text { Crisálida do } \\
\text { bicho da seda } \\
\text { desidratada }\end{array}$ & CV (\%) & p-valor \\
\hline $\mathrm{Vcnf}^{1}(\mathrm{~mL})$ & $36,69 \mathrm{a}$ & $23,03 \mathrm{~b}$ & $10,09 \mathrm{c}$ & $5,91 \mathrm{~d}$ & $8,94 \mathrm{c}$ & 9,51 & $<0,0001$ \\
$\mathrm{Kcnf}^{2}\left(\mathrm{~h}^{-1}\right)$ & $0,0976 \mathrm{~b}$ & $0,0706 \mathrm{~b}$ & $0,1481 \mathrm{~b}$ & $0,3998 \mathrm{a}$ & $0,0505 \mathrm{~b}$ & 102,76 & $<0,0001$ \\
$\mathrm{~L}^{3}(\mathrm{~h})$ & $2,52 \mathrm{a}$ & $2,04 \mathrm{a}$ & $3,17 \mathrm{a}$ & $8,90 \mathrm{~b}$ & $2,67 \mathrm{a}$ & 21,82 & $<0,0001$ \\
$\mathrm{Vcf}^{4}(\mathrm{~mL})$ & $41,47 \mathrm{a}$ & $29,20 \mathrm{c}$ & $41,46 \mathrm{a}$ & $32,67 \mathrm{~b}$ & $12,87 \mathrm{~d}$ & 7,18 & $<0,0001$ \\
$\mathrm{Kcf}^{5}\left(\mathrm{~h}^{-1}\right)$ & $0,0230 \mathrm{a}$ & $0,0156 \mathrm{c}$ & $0,0237 \mathrm{a}$ & $0,0184 \mathrm{~b}$ & $0,0048 \mathrm{~d}$ & 9,49 & $<0,0001$ \\
\hline
\end{tabular}

Letras diferentes nas linhas diferem entre si pelo teste SNK a 5\% de probabilidade. ${ }^{1}$ Venf - volume de gás produzido pela degradação dos carboidratos não fibrosos, ${ }^{2} \mathrm{Kcnf}$ - taxa de degradação dos carboidratos não fibrosos, ${ }^{3} \mathrm{~L}$ - período de latência, ${ }^{4} \mathrm{Vcf}$ - volume de gás produzido pela degradação dos carboidratos fibrosos, ${ }^{5} \mathrm{Kvf}$ - taxa de degradação dos carboidratos fibrosos.

Fonte: Elaboração dos autores.

O farelo de nabo forrageiro foi o único alimento que diferiu dos demais no tempo de colonização dos microrganismos com $6,4 \mathrm{~h}$, ao passo que os demais variaram entre 1,7 e 2,7h. Esse maior tempo de colonização somado ao elevado coeficiente de variação apresentado por essa variável, pode ser decorrente do animal doador de inóculo ruminal, que dependendo do estado nutricional, fonte de alimento recebido, estado fisiológico, pode apresentar diferenças no potencial fermentativo do inóculo.

Conforme Theodorou et al. (1994) e Pell, Schofield e Stone (1994), se o propósito for a estimativa das taxas de degradação, a técnica de produção cumulativa de gás apresenta-se como simples, barata e precisa. Segundo Malafaia et 
al. (1998) a comparação de alimentos deve ser feita sempre por técnicas in vitro, ao passo que a comparação entre dietas, por técnicas in vivo.

\section{Conclusão}

Para a maioria dos alimentos avaliados houve sincronismo entre as frações de carboidratos e compostos nitrogenados, o que favorece o aproveitamento de nutrientes, a redução da excreção de compostos nitrogenados no ambiente, bem como a potencialização do crescimento microbiano.

O farelo de Crambe apresenta predominância das frações A+B1 dos carboidratos e B1+B2 dos compostos nitrogenados, não apresentando sincronismo entre as frações nitrogenadas e carboidratos.

Os parâmetros obtidos pela produção cumulativa de gases permitem inferir que o farelo de soja é o melhor alimento avaliado, no entanto todos os demais apresentam potencial para utilização na nutrição animal. A técnica cumulativa de produção de gases possibilita a estimativa das taxas de degradação e fornece informações adicionais sobre a cinética de fermentação ruminal dos alimentos.

\section{Agradecimentos}

Os autores expressam agradecimentos à Indústria de Bebidas Zanni Ltda; à Fiação de Seda Bratac S/A e à Fundação MS pela doação do resíduo úmido de cervejaria; da crisálida do bicho da seda desidratado e do farelo de crambe, respectivamente.

\section{Referências}

ANDERSON, V. L.; SLANGEL, W. D.; BOYLES, S. L.; BERG, P. T. Crambe meal is equivalent to soybean meal for backgrounding and finishing beef steers. Journal of Animal Science, Champaign, v. 71, n. 10, p. 2608-2613, 1993.

BARCELOS, A. F.; PAIVA, P. C. A.; PEREZ, J. R. O.; TEIXEIRA, J. C.; CARDOSO, R. M.; SANTOS, V. B. Avaliação da casca e da polpa desidratada de café (Coffea arabica 1.) pela técnica de degradabilidade in vitro de produção de gases. Revista Brasileira de Zootecnia, Viçosa, v. 30, n. 6, p. 1829-1836, 2001.

BEZERRA, A. R. G. F.; MALAFAIA, P. A. M.; MANCINI, M. C.; BEZERRA, E. S.; VIEIRA, R. A. M. Parâmetros cinéticos da degradação in vitro de alimentos incubados com inóculo microbiano de diferentes espécies de ruminantes. Arquivo Brasileiro de Medicina Veterinária e Zootecnia, Belo Horizonte, v. 57, n. 4, p. 494-501, 2005.

CABRALFILHO, S. L. S.; BUENO, I. C. S.; ABDALLA, A. L. Substituição do feno de Tifton pelo resíduo úmido de cervejaria em dietas de ovinos em mantença. Ciência Animal Brasileira, Goiânia, v. 8, n. 1, p. 75-73, 2007.

CABRAL, L. S.; VALADARES FILHO, S. C.; DETMANN, E.; ZERVOUDAKIS, J. T.; PEREIRA, O. G. P.; VELOSO, R. G.; PEREIRA, E. S. Cinética Ruminal das Frações de carboidratos, produção de gás, digestibilidade In Vitro da matéria seca e NDT estimado da silagem de milho com diferentes proporções de grãos. Revista Brasileira de Zootecnia, Viçosa, v. 31, n. 6, p. 2332-2339, 2002.

CABRAL, L. S.; VALADARES FILHO, S. C.; MALAFAIA, P. A. M.; LANA, R. P.; SILVA, J. F. C.; VIEIRA, R. A. M.; PEREIRA, E. S. P. Frações de carboidratos de alimentos volumosos e suas taxas de degradação estimadas pela técnica de produção de gases. Revista Brasileira de Zootecnia, Viçosa, v. 29, n. 6, p. 2087-2098, 2000.

CAMPOS, F. P.; BOSE, M. L. V.; BOIN, C.; LANNA, D. P. D.; MORAIS, J. P. G. Avaliação do sistema de monitoramento computadorizado de digestão in vitro. 3. Desaparecimento da matéria seca e/ou FDN pela produção de gás. Revista Brasileira de Zootecnia, Viçosa, v. 29 , n. 2 , p. $537-544,2000$.

COLL, J. F. C.; CRESPI, M. P. A. L; ITAGIBA, M. G. O. R.; SOUSA, J. C. D.; GOMES, A. V. D.; DONATTI, F. C. Uso da farinha de crisálida do bicho da seda (Bombyx mori L.) como fonte de proteína na alimentação de suínos em crescimento - terminação. Revista da Sociedade Brasileira de Zootecnia, Viçosa, v. 21, n. 3, p. 378-384, 1992.

CONE, J. W.; VAN GELDER, A. H.; DRIEHUIS, F. Description of gas production profiles with a threephasic model. Animal Feed Science and Technology, Amsterdam, v. 66, n. 1, p. 31-45, 1997.

EASTRINDGE, M. L. Alternative feeds. In: OHIO DAIRY NUTRITION CONFERENCE, 1991, Wooster. Proceedings... Wooster: M. L. Eastrindge and Others, 1991. p. 49-63. 
FERNANDES, J. J. R.; VAZ PIRES, A.; OLIVEIRA JUNIOR, R. C.; SANTOS, F. A. P.; SUSIN, I.; CARVALHO, E. R. Farelo de soja em substituição à ureia em dietas para bovinos de corte em crescimento. Ciência Animal Brasileira, Goiânia, v. 10, n. 2, p. 373-378, 2009.

GERON, L. J. V.; ZEOULA, L. M.; BRANCO, A. F.; ERKE, J. A.; PRADO, O. P. P.; JACOBI, G. Caracterização, fracionamento protéico, degradabilidade ruminal e digestibilidade in vitro da matéria seca e proteína bruta do resíduo de cervejaria úmido e fermentado. Acta Scientiarum Animal Sciences, Maringá, v. 29, n. 3, p. 291-299, 2007.

LIMA, G. J. M. M.; GOMES, P. C.; FERREIRA, A. S.; LAZZARETTTI, D.; CRIPPA, J. Valores de digestibilidade e composição química e bromatológica de alguns alimentos para suinos. Concórdia: EMBRAPA/ CNPSA, abr. 1990, p. 1-3. (Comunicado técnico, 152).

MALAFAIA, P. A. M.; VALADARES FILHO, S. C.; VIEIRA, R. A. M.; SILVA, J. F. C.; PEREIRA, J. C. Cinética ruminal de alguns alimentos investigada por técnicas gravimétricas e metabólicas. Revista Brasileira de Zootecnia, Viçosa, v. 27, n. 2, p. 370-380, 1998.

MALAFAIA, P. A. M.; VIEIRA, R. A. M. Técnicas de determinação e avaliação dos compostos nitrogenados em alimentos para ruminantes. In: SIMPÓSIO INTERNACIONAL DE DIGESTIBILIDADE EM RUMINANTES, 1997, Lavras, MG. Anais... Lavras, MG: [s. n], 1997.p. 29-54.

McDOUGAL, E. I. Studies on ruminal saliva. The composition and output of sheep's saliva. Biochemical Journal, London, v. 43, n. 1, p. 99-109, 1949.

MELLO, R.; NÖRNBERG, J. L.; QUEIROZ, A. C.; MIRANDA, E. N.; MAGALHÃES, A. L. R.; DAVID, D. B.; SARMENTO, J. L. R. Composição química, digestibilidade e cinética de degradação ruminal das silagens de híbridos de girassol em diferentes épocas de semeadura. Revista Brasileira de Zootecnia, Viçosa, v. 35, n. 4, p. 1523-1534, 2006.

MIZUBUTI, I. Y.; PINTO, A. P.; PEREIRA, E. S.; RAMOS, B. M. O. Métodos laboratoriais de avaliação de alimentos para animais. Londrina: EDUEL, 2009. v. 1. $228 \mathrm{p}$.

MIZUBUTI, I. Y.; RIBEIRO, E. L. A.; PEREIRA. E. S.; PINTO, A. P.; FRANCO, A. L. C. F.; SYPRERRECK, M. A.; DÓREA, J. R. R.; CUNHA, G. E.; CAPELARI, M. M.; MUNIZ, E. B. Cinética de fermentação ruminal in vitro de alguns co-produtos gerados na cadeia produtiva do biodiesel pela técnica de produção de gases. Semina: Ciências Agrárias, Londrina, v. 32, p. 2021-2028, 2011. Suplemento 1.
MOREIRA, P. C.; REIS, R. B.; REZENDE, P. L. P.; WASCHECK, R. C.; MENDONÇA, A. C.; DUTRA, A. R. Produção cumulativa de gases e parâmetros de France avaliados pela técnica semiautomática in vitro de fontes de carboidratos de ruminantes. Revista Brasileira de Saúde e Produção Animal, Salvador, v. 11, n. 2, p. 452462, 2010.

MORENZ, M. J. F. Avaliação do modelo CNCPS (Cornell Net Carbohydrate and Protein System) na estimativa do consumo de matéria seca e da produção de leite de vacas mestiças em pastagem de capim-elefante (Pennisetum purpureum schum., cv. napier). 2004. Tese (Doutorado em Produção Animal) - Universidade Estadual Norte Fluminense. Campos dos Goytacazes, Goytacazes.

NATIONAL RESEARCH COUNCIL - NRC. Nutrient requirements of dairy cattle. 7. ed. Washington. DC: National Academy Press. 2001. 381 p.

NOCEK, J.; RUSSELL, J. B. Protein and carbohydrate as an integrated system. Relationship of ruminal availability to microbial contribution and milk production. Journal of Dairy Science, Madison, v. 71, n. 8, p. 2070-2107, 1988.

PELL, A. N.; SCHOFIELD, P. Computerized monitoring of gas production to measure forage digestion in vitro. Journal of Dairy Science, Madison, v. 76, n. 9, p. 10631073, 1993.

PELL, A. N.; SCHOFIELD, P.; STONE, W. C. Rates of digestion of feeds measured in vitro with computers. CORNELL NUTRITION CONFERENCE, 1997, Cornell University. Proceedings... Cornell University, 1994. p. 74-81.

PEREIRA, E. S.; ARRUDA, A. M. V.; MIZUBUTI, I. Y.; Villarroel, A. B. S.; PIMENTEL, P. G. Determinação da digestibilidade intestinal de alimentos pela técnica de três estágios. Semina: Ciências Agrárias, Londrina, v. 29, n. 2, p. 431-440, 2008.

PERRY, T. W.; KWOLEK, W. F.; TOOKEY, H. L.; PRINCEN, L. H.; BEESON, W. M.; MOHLER, M. T. Crambe meal as a source of supplemental protein for growing-finishing beef cattle. Journal of Animal Science, Champaign, v. 48, n. 4, p.758-763, 1979.

RUSSELL, B. J.; O'CONNOR, J. D.; FOX, D. J.; VAN SOEST, P. J.; SNIFFEN, C. J. A net carbohydrate and protein system for evaluation cattle diets: ruminal fermentation. Journal of Dairy Science, Madison, v. 70, n. 12, p. 3551-3581, 1992.

SANTOS, V. G.; FERNANDES JÚNIOR, A. C.; KOCK, J. F. A.; BARROS, M. M.; GUIMARÃES, I. G.; PEZZATO, L. E. Composição química e digestibilidade do farelo de nabo forrageiro para tilápia do Nilo. Revista 
Brasileira de Saúde e Produção Animal, Salvador, v. 11, n. 2, p. 537-546, 2010.

\section{STATISTICAL ANALYSIS SYSTEM INSTITUTE -}

SAS. Software, version 6.0. Cary: SAS Institute, 2009.

SCHOFIELD, P.; PITT, R. E.; PELL, A. N. Kinetics of fiber digestion from in vitro gas production. Journal of Animal Science, Champaign, v. 72, n. 11, p. 2980-2991, 1994.

SILVA, V. B.; FONSECA, C. E. M.; MORENZ, M. J. F.; PEIXOTO, E. L. T.; MOURA, E. S.; CARVALHO, I. N. O. Resíduo úmido de cervejaria na alimentação de cabras. Revista Brasileira de Zootecnia, Viçosa, v. 39, n. 7, p. 1595-1599, 2010.

SNIFFEN, C. J.; O'CONNOR, J. D.; VAN SOEST, P. J.; FOZ, D. G.; RUSSELL, J. B. A net carbohydrate and protein system for evaluating cattle diets: II. Carbohydrate and protein availability. Journal of Animal Science, Champaign, v. 70, n. 7, p. 3562-3577, 1992.
STEFANON, B.; PELL, A. N.; SCHOFIELD, P. Effect of maturity on digestion kinetics of water-soluble and water insoluble fractions of alfafa and brome hay. Journal of Animal Science, Champaign, v. 74, n. 5, p. 1104-1115, 1996.

THEODOROU, M. K.; WILLIAMS, B. A.; DSHANOA, M. S.; McALLANA, A. B.; FRANCE, J. simple gas production method using a pressure transducer to determine the fermentation kinetics of ruminant feed. Animal Feed Science and Technology, Amsterdam, v. 48, n. 1, p. 185-197, 1994.

VALADARES FILHO, S. C. Nutrição, avaliação de alimentos e tabelas de composição de alimentos para bovinos. In: REUNIÃO ANUAL DA SOCIEDADE BRASILEIRA DE ZOOTECNIA, 37., 2000, Viçosa, MG. Anais... Viçosa, MG: Sociedade Brasileira de Zootecnia, 2000, p. 267. 